\section{UPAYA PENINGKATAN}

KEMAMPUAN COMPUTATIONAL THINKING SISWA DI SMP NOAH

Agustine Dwianika', Ceicillia Novita Roseline $^{2}$, Meika Priscilia ${ }^{3}$, Padia Aqilla Haya $^{4}$

\section{1,2,3,4 Universitas Pembangunan Jaya \\ * Agustine Dwianika \\ Email : Agustine.dwianika@upj.ac.id}

\begin{abstract}
This Community Service activity aims to improve students' analytical skills using computer-based Thinking. Computational Thinking is a method of solving problems by applying computer science techniques (informatics). This activity is a display of hands from the Bebras Bureau of Pembangunan Jaya University to provide training for teachers so that later they can become proficient in making questions for students. Of course, with adequate computational thinking adoption skills. We conduct training for teachers at NOAH Junior High School (SMP) in Jakarta. This training implementation method uses three ways, namely introduction, implementation, and evaluation. The activity went online well, and participants gained a broad understanding of the value adoption of Computational Thinking for junior secondary school teachers.

Keywords: Computational Thinking, Education, Learning
\end{abstract}

\begin{abstract}
Abstrak
Kegiatan Pengabdian Masyarakat ini bertujuan untuk meningkatkan kemampuan analisa siswa dengan cara pikir berbasis komputer. Berpikir komputasional (Computational Thinking) adalah metode menyelesaikan persoalan dengan menerapkan teknik ilmu komputer (informatika). Kegiatan ini merupakan perpajangan tangan dari Biro Bebras Universitas Pembangunan Jaya dalam upaya memberikan pelatihan bagi guru, sehingga nantinya dapat mahir dalam pembuatan soal bagi para siswa. Tentu dengan kecakapan adopsi berpikir komputasional yang memadai. Kami melaksanakan pelatihan bagi para guru pada Sekolah Mengah Pertama (SMP) NOAH di Jakarta. Metode pelaksanaan pelatihan ini memakai 3 cara yaitu pendahuluan, pelaksanaan dan evaluasi. Kegiatan berjalan secara daring dengan baik, dan para peserta mendapatkan pemahaman luas mengenai adopsi nilai-nilai berfikir komputasional bagi para guru sekolah tingkat menengah pertama.

Kata Kunci: Berpikir Komputasional, Pendidikan, Pembelajaran
\end{abstract}


UPAYA PENINGKATAN KEMAMPUAN COMPUTATIONAL THINKING SISWA DI SMP NOAH

Agustine Dwianika, Ceicillia Novita Roseline, Meika Priscilia, Padia Aqilla Haya

Volume 1, No. 1, April 2021 hal. 60-68

DOI Artikel : 10.46306/jub.v1i1.14

\section{PENDAHULUAN}

Di era globalisasi, suatu pembelajaran menjadi suatu hal yang terpenting bagi keberlanjutan dan keberlangsungan pendidikan di Indonesia. Berbagai cara dan upaya telah dilakukan untuk meningkatkan proses pembelajaran bagi peserta didik di Indonesia. Hal ini dilakukan untuk membantu para peserta didik di dalam mendapatkan berbagai ide, informasi dan cara berpikir serta meningkatkan keterampilan dalam menganalisis. Salah satu upaya pembelajaran yang dapat dilakukan selain membekali kemampuan dengan membaca, aritmetika dan menulis, yaitu dengan memperkenalkan dan mempelajari metode Computational Thinking kepada para peserta didik.

Computational Thinking (CT) atau berpikir komputasi merupakan suatu metode atau pembelajaran yang mengandalkan bagaimana cara proses berpikir yang diperlukan dalam pemecahan dan penyelesaian suatu masalah. Wing (2006) mendefinisikan Computational Thinking sebagai penyelesaian masalah, merancang sebuah sistem dan memahami perilaku manusia dalam menggambarkan suatu konsep dasar ke dalan computer science. Menurut Wing (2006: 33-35), Kemampuan problem solving ini dirancang sebagai suatu sistem yang bertujuan untuk memahami bagaimana perilaku manusia dengan cara mengambil beberapa konsep dasar dari ilmu komputer. Sekarang ini, banyak sekolah-sekolah di Indonesia maupun luar negeri yang mulai menerapkan metode Computational Thinking ini. Metode ini merupakan hasil rujukan dari ide dan konsep penerapan di berbagai bidang computer science atau teknik informatika. Wing (2008:37I7-37/8) berpendapat bahwa inti dari metode Computational Thinking adalah kemampuan abstraksi. Di dalam proses komputasi, abstraksi menjadi lebih kompleks dibandingkan matematika dan Fisika. Hal ini terjadi karena abstraksi tidak secara jelas menyebutkan dan mendefinisikan suatu variabel di dalam matematika maupun Fisika, seperti bilangan asli atau a

Dengan memiliki kemampuan problem solving dan menggunakan metode Computational Thinking, maka dapat berguna dan menjadi modal yang penting bagi anak-anak atau pelajar, khususnya pelajar di Indonesia, agar dapat mampu bersaing di dunia kerja secara lingkup nasional maupun global. Menyadari betapa pentingnya kemampuan problem solving di dalam berbagai ilmu kehidupan, maka dibuatkanlah suatu program sebagai upaya peningkatan kemampuan Computational Thinking yaitu dengan mengadakan sebuah kampanye edukasi Computational Thinking di berbagai sekolah melalui Komunitas Bebras. Program ini mulai dikampanyekan pada tahun 2006 di Indonesia dan telah secara aktif berpartisipasi dalam mengampanyekan edukasi CT. Sebelumnya, Bebras.org sudah ada sejak 2005 di Ukraina dan secara berkala telah mengadakan Bebras Challenge, sebagai media edukasi kepada anak-anak dan pelajar mulai dari sekolah dasar hingga menengah mengenai konsep berpikir secara komputasional. 
UPAYA PENINGKATAN KEMAMPUAN COMPUTATIONAL THINKING SISWA DI SMP NOAH

Agustine Dwianika, Ceicillia Novita Roseline, Meika Priscilia, Padia Aqilla Haya

Volume 1, No. 1, April 2021 hal. 60-68

DOI Artikel : 10.46306/jub.v1i1.14

Biro Bebras Universitas Pembangunan Jaya (UPJ) yang dikelola secara langsung oleh Universitas Pembangunan Jaya juga turut ikut andil dan berpartisipasi di dalam kegiatan kampanye edukasi Computational Thinking. Di tahun 202I ini, Biro Bebras UPJ menyelenggarakan pengenalan serta pelatihan CT kepada guru dan siswa sekolah, salah satunya di SMP Noah. Pada pengenalan dan pelatihan CT kali ini dilakukan secara tatap muka secara virtual atau daring (online) melalui aplikasi Zoom dikarenakan masih di masa pandemi COVID-I9.

\section{METODE PENGABDIAN}

Metode pengabdian yang dilakukan meliputi 3 tahapan yaitu pendahuluan, pelaksanaan dan evaluasi. Pendahuluan dilakukan oleh Biro Bebras UPJ dengan penjajakan kerjasama dan penggalian kebutuhan pelatihan berbasis komputasional kepada para guru di SMP NOAH. Setelah ditemukan kebutuhan tersebut, dilanjutkan dengan tahapan pelaksanaan pelatihan dan diakhiri dengan evaluasi.

Butuh waktu relatif tidak cepat bagi Biro Bebras UPJ untuk menemukan sekolah yang sesuai dengan kriteria yang harus dipenuhi dalam upaya penyelenggaraan kegiatan ini. Setelah 3-4 bulan mencari akhirnya SMP NOAH menjadi salah satu sekolah yang mendukung dengan baik. Barangkali karena tidak semua sekolah telah mengadaptasi materi pelajaran berbasis komputasional.

Setelah itu dilanjutkan dengan penjajakan kebutuhan sekolah akan program komputational yang diperlukan. Dan ditemukanlah bahwa adaptasi kemampuan berfikir komputasional siswa menjadi tantangan tersendiri pada sekolah ini.

Tindaklanjut dari penjajakan ini adalah terlaksananya program pelatihan Computational Thinking (CT) dalam upaya menggali kemampuan para guru dalam mengadopsi aspek-aspek komputasi yang dimilikinya. Dan kemudian dituangkannya dalam pembuatan soal. Kemudian, tahapan akhir adalah evaluasi dari kegiatan yang telah dilakukan berupa uji peningkatan cara berfikir berbasis komputasi para guru. Yang dibuktikan dengan soal-soal yang dibuat dengan muatan $\mathrm{CT}$ sesuai dengan mata pelajaran yang diampu.

\section{PELAKSANAAN DAN PEMBAHASAN}

Pelaksanaan kegiatan pelatihan Computational Thinking ini diawali dengan pelaksanaan seminar dan dimulai pada tanggal 26 Februari 202I - 2 Maret 202I. Pelatihan yang dilakukan setiap satu minggu sekali ini diikuti oleh lbu / Bapak Guru yang mengampu mata pelajaran yang berbeda dan dibagi dalam beberapa kelompok sesuai dengan mata pelajaran yang diampu. Kelompok yang mengikuti pelatihan dengan kami adalah ibu / bapak guru dengan jabatan Kepala Sekolah, Wakil Kepala Sekolah, pengajar mata pelajaran Bahasa Inggris dan guru Bimbingan Konseling. 


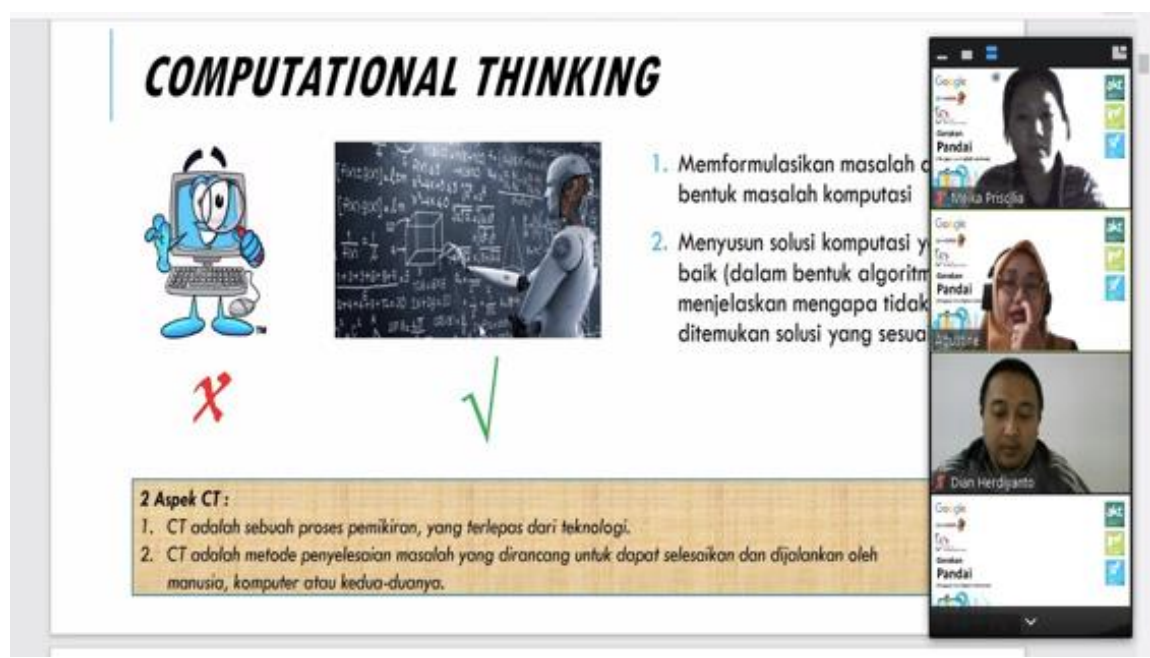

Gambar I. Pelaksanaan Pelatihan Tahap I

Pelatihan computational thinking yang dilakukan ini mengacu pada kurikulum Pelatihan Bebras Indonesia. Setiap minggunya, ibu / bapak guru peserta pelatihan akan bertemu dengan mentor yang nantinya memberikan materi pelatihan dan melakukan diskusi terkait dengan materi pelatihan. Pertemuan dilakukan secara online menggunakan aplikasi Zoom Meeting. Pada kegiatan ini, peserta pelatihan akan diberikan beberapa macam soal dan diminta untuk menjawab beserta dengan pembahasannya. Hal ini bertujuan untuk mengasah kemampuan berpikir secara komputasional bagi peserta pelatihan.

Selain diberikan materi dengan soal dan pembahasan, setiap minggunya setelah pelatihan, mentor akan memberikan tugas yang berkaitan dengan materi yang dibahas. Tujuannya adalah untuk mempersiapkan ibu / bapak guru dalam pembuatan soal computational thinking untuk siswa-siswi di sekolahnya dengan menyesuaikan mata pelajaran yang diampu. Untuk materi dan tugas, diberikan melalui aplikasi Google Documents dan juga Collabor yang dapat diakses menggunakan user id dan password yang telah diberikan.

\section{Pengenalan materi Computational Thinking}

Rencana awal dari pelaksanaan kegiatan bebras ini adalah memberi wawasan kepada para Ibu/Bapak guru SMP Noah agar dapat berpikir secara komputerisasi serta meningkatkan kemampuan problem solving terhadap sebuah masalah. Pemikiran komputasi menekankan pada proses berpikir tingkat tinggi (high order thinking) bukan pada performa nyata seperti portofolio ataupun bukti nyata lainnya. Hal itu bisa jadi suatu masalah tersendiri dalam penilaiannya agar diperoleh hasil yang tepat. Proses berpikir dalam pemikiran komputasi seperti abstraksi, dekomposisi, generalisasi, analisa kritis dalam menemukan solusi permasahan dan menyingkirkan 
UPAYA PENINGKATAN KEMAMPUAN COMPUTATIONAL THINKING SISWA DI SMP NOAH

Agustine Dwianika, Ceicillia Novita Roseline, Meika Priscilia, Padia Aqilla Haya

Volume 1, No. 1, April 2021 hal. 60-68

DOI Artikel : 10.46306/jub.v1i1.14

hambatan-hambatan di dalamnya semua terjadi secara aktual dalam otak siswa sehingga menimbulkan kesulitan dalam pengukurannya. berikut adalah beberapa hasil dokumentasi dalam pengenalan materi Computational Thinking

\section{MEMAHAMI ASPEK-ASPEK CT}

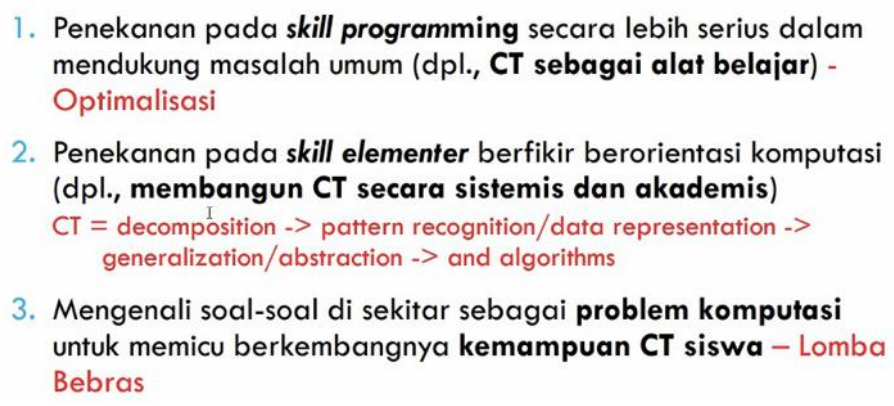

Penekanan pada skill programming secara lebih serius dalam mendukung masalah umum (dpl., CT sebagai alat belajar) Optimalisasi

2. Penekanan pada skill elementer berfikir berorientasi komputasi (dpl., membangun CT secara sistemis dan akademis)

CT = decomposition -> pattern recognition/data representation -> generalization/abstraction -> and algorithms

3. Mengenali soal-soal di sekitar sebagai problem komputasi untuk memicu berkembangnya kemampuan CT siswa - Lomba Bebras

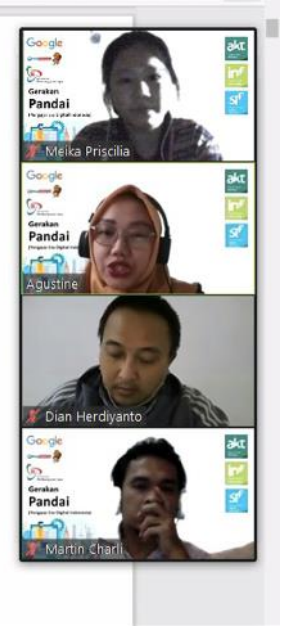

Gambar 2. Pelaksanaan Pelatihan Tahap 2

\section{TUJUAN PELATIHAN}

1. Memahami aspek-aspek $\mathrm{C}$ dan keterkaitan dengan bidang keilmuan lain

2. Mempelajari karakteristik CT melalui soal bebras

3. Memahami langkah penyusunan soal dengan muatan $C T$

4. Mengintegrasikan CT dalam berbagai bidang pelajaran

Gambar 3. Pelaksanaan Pelatihan Tahap 3

Berdiskusi dan pelatihan membuat soal Computational Thinking

Dengan mengikuti pelatihan ini. Diharapkan bapak/ ibu guru dapat memahami bagaimana cara membuat soal dengan tingkatan High Order Thinking (hots) serta mempersiapkan materi Asesmen Kompetensi Minimum (AKM) yang nantinya berguna untuk kegiatan asesmen pada tingkat sekolah. Di Indonesia sendiri masih sedikit kajian pemikiran komputasi apalagi praktik pelaksanaannya di sekolah juga belum banyak diterapkan. Penilaian terhadap kemampuan esensial ini pun otomatis belum bayak terpikirkan. Namun demikian, dengan adanya diskusi dan pelatihan membuat soal mengenai computational thinking sekaligus memberikan gambaran yang matang 
UPAYA PENINGKATAN KEMAMPUAN COMPUTATIONAL THINKING SISWA DI SMP NOAH

Agustine Dwianika, Ceicillia Novita Roseline, Meika Priscilia, Padia Aqilla Haya

Volume 1, No. 1, April 2021 hal. 60-68

DOI Artikel : 10.46306/jub.v1i1.14

secara teoritis bagaimana pembelajaran yang melatih kemampuan ibu/ bapak guru dalam melaksanakan sekaligus menunjukkan bagaimana penilaian yang efektif dalam mengukur kemampuan siswa, berikut adalah dokumentasi berdiskusi dalam pelatihan membuat soal Computational Thinking.

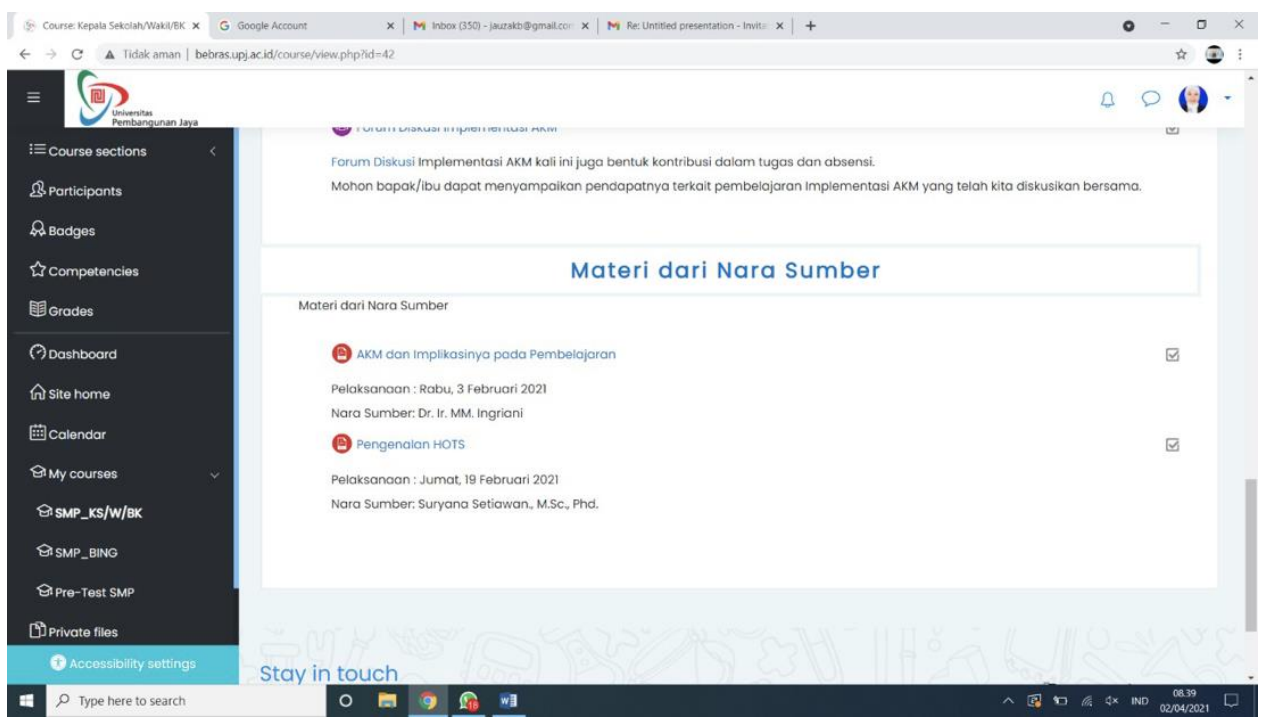

Gambar 4. Menyiapan Materi Latihan dalam Sistem UPJ

Bebras Indonesia - Kelompok Penggalang

\begin{tabular}{|c|c|c|}
\hline Negara & Nomer dan Judul Soal & Kode Soal \\
\hline & \multirow{2}{*}{ 1. Resep Rahasia } & 2016-HU-02 \\
\cline { 3 - 3 } & & Sumber : \\
\cline { 3 - 3 } & & \\
\hline
\end{tabular}

\section{Deskripsi Soal}

Keluarga Berang-berang sedang mempersiapkan acara Festival Makanan, dan mereka ingin memanggang kue kering; Kati akan membuat kue. Dia sangat memperhatikan urutan membuat kue dengan memasukkan bahan kue dengan urutan yang benar.

Ketika dia berjalan ke taman, dia melihat ada secarik kertas petunjuk pada setiap bahan kue yang akan digunakan. Gambar pada kertas petunjuk menjelaskan bahan kue yang harus ditambahkan pada urutan berikutnya. Hanya ada satu bahan kue yang tidak memiliki kertas. Ilustrasi taman seperti di bawah ini:

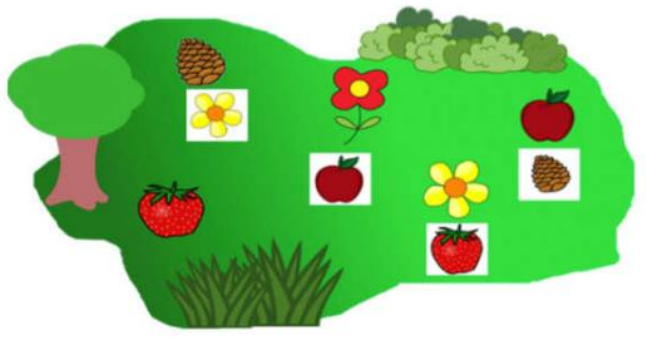

Gambar 5. Salah Satu Contoh Pembahasan Materi Soal 


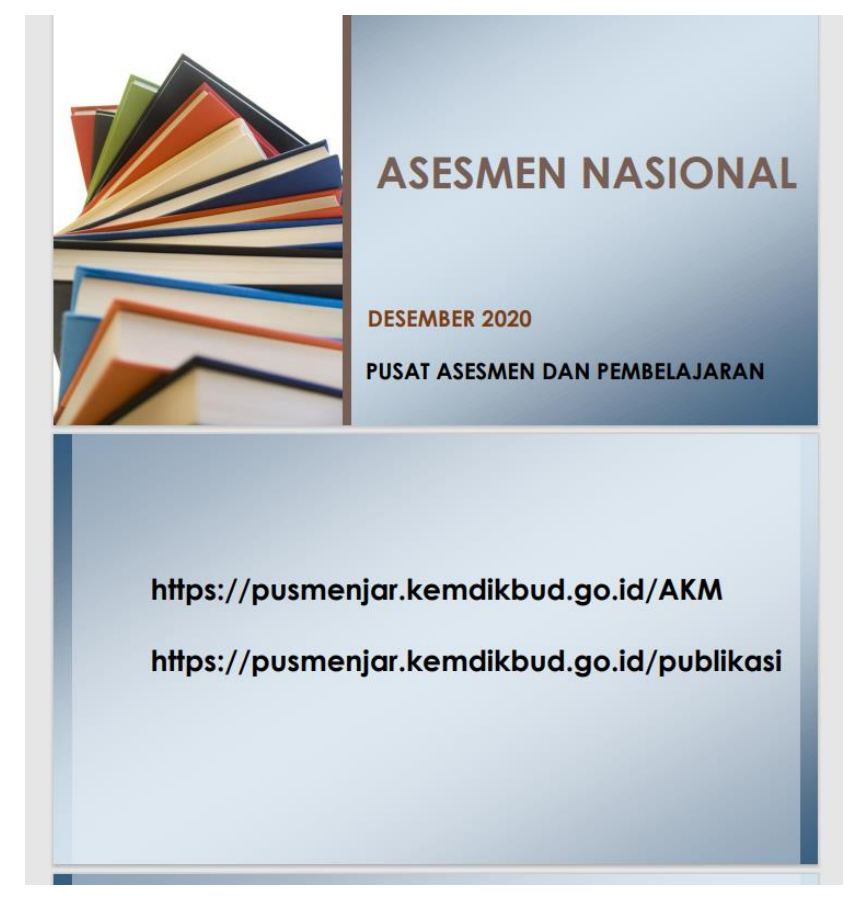

Gambar 6. Sinkroniasi Materi dan Kurikulum Terbaru

\section{KESIMPULAN DAN SARAN}

Kegiatan ini sangat bermanfaat bagi peningkatan kemampuan komputasional para guru SMP NOAH. Untuk kemudian telah dapat merumuskan soal-soal bermuatan kemampuan komputasi dan melatihnya kepada para siswa didik. Namun, pelaksanaan pelatihan secara luring memiliki kendala tersendiri bagi beberapa guru. Terdapat guru yang lebih menginginkan pelatihan langsung (offline), sehingga implementasi dalam soal lebih mudah dipahami. Kedepan, perlu dievaluasi lebih lanjut dan pendampingan intensif kegiatan ini, sehingga dapat dilihat seberapa efektif program ini bagi para siswa.

\section{UCAPAN TERIMA KASIH}

Terima kasih kepada Biro Bebras Universitas Pembangunan Jaya yang telah memberikan kesempatan bagi pelaksana untuk berkontribusi bagi para pendidik, dan juga LP2M Universitas Pembangunan Jaya yang telah mendukung publikasi ini. Tak lupa kepada Sekolah NOAH atas partisipasinya dalam kegiatan ini, serta seluruh mahasiswa UPJ yang terlibat dalam pelaksanaan dan publikasi ini. 
UPAYA PENINGKATAN KEMAMPUAN COMPUTATIONAL THINKING SISWA DI SMP NOAH

Agustine Dwianika, Ceicillia Novita Roseline, Meika Priscilia, Padia Aqilla Haya

Volume 1, No. 1, April 2021 hal. 60-68

DOI Artikel : 10.46306/jub.v1i1.14

\section{DAFTAR PUSTAKA}

Friantini, R. N, dkk. (2020). PENGUATAN KONSEP MATEMATIKA DASAR PADA ANAK USIA SKEOLAH DASAR. Jurnal Abdimas Bina Bangsa I(2): 276-285

Gais, Z., \& Afriansyah, E. A. (2018). ANALISIS KEMAMPUAN SISWA DALAM MENYELESAIKAN SOAL HIGH ORDER THINKING DITINJAU DARI KEMAMPUAN AWAL MATEMATIS SISWA. Mosharafa: Jurnal Pendidikan Matematika, 6(2), 255-266. doi:10.31980/mosharafa.v6i2.313

Hidayat, E. Y, dkk. (2020). PEMBELAJARAN COMPUTATIONAL THINKING UNTUK SISWA SMA INSTITUT INDONESIA SEMARANG. Jurnal Abdimasku 3(3): 93-98

Kawuri, K. R, dkk. (2019). PENERAPAN COMPUTATIONAL THINKING UNTUK MENINGKATKAN KEMAMPUAN BERPIKIR KRITIS SISWA KELAS X MIA 9 SMA NEGERI I SURAKARTA PADA MATERI USAHA DAN ENERGI 6. Jurnal Materi dan Pembelajaran Fisika 9(2): I|6-I2I

Kuswanto, H., Rodiyanti, N., Kholisho, Y. N., ... Arianti, B. D. D. (2020). Pengaruh Kemampuan Matematika Terhadap Kemampuan Computational Thinking Pada Anak Usia Sekolah Dasar. Educatio, I5(2), 78-84. doi:I0.29408/edc.v15i2.29I6

Nurhopipah, A., Nugroho, I. A., \& Suhaman, J. (202I). PEMBELAJARAN PEMROGRAMAN BERBASIS PROYEK UNTUK MENGEMBANGKAN KEMAMPUAN COMPUTATIONAL THINKING ANAK. JURNAL PENGABDIAN KEPADA MASYARAKAT, 27(I), 6. doi:I 0.24I I 4/jpkm.v27il.2I29I

Pamungkas, M. D, dkk. (2020). WORKSHOP PENGGUNAAN SOFTWARE GEOGEBRA SEBAGAI MEDIA PEMBELAJARAN MATEMATIKA BAGI GURU SD/MI. Jurnal Abdimas Bina Bangsa I(2): I75-I85

Putra, M. R. A. L, dkk. (2019). PENERAPAN KEMAMPUAN PROBLEM SOLVING PADA SISWA SMP MENGGUNAKAN PENDEKATAN COMPUTATIONAL THINKING (CT) BERBASIS ROLE PLAYING GAME (RPG). Jurnal Ilmiah Teknik Informatika 8(2): I58-164 Selegi, S. F. (2020). ANALISIS KEMAMPUAN HIGHER ORDER THINKING SKILL (HOTS) MELALUI CREATIVE PROBLEM SOLVING (CPS) UNTUK MENINGKATKAN KEMAMPUAN KOGNITIF MAHASISWA. doi:I0.31219/osf.io/4zag6

Sukamto, T. S, dkk. (2019). PENGENALAN COMPUTATIONAL THINKING SEBAGAI METODE PROBLEM SOLVING KEPADA GURU DAN SISWA SEKOLAH DI KOTA SEMARANG. Jurnal Abdimasku 2(2): 99-107 
UPAYA PENINGKATAN KEMAMPUAN COMPUTATIONAL THINKING SISWA DI SMP NOAH

Agustine Dwianika, Ceicillia Novita Roseline, Meika Priscilia, Padia Aqilla Haya

Volume 1, No. 1, April 2021 hal. 60-68

DOI Artikel : 10.46306/jub.v1i1.14

Wardhani, I. Y. (20I8). Pembelajaran Thinking Actively In Social Context Untuk Meningkatkan Kemampuan Higher Order Thinking Siswa SMA. Journal Of Biology Education, I(I), I. doi:I0.21043/jobe.vlil.3532 